\title{
Concentrações de ácido indolbutírico na propagação do umezeiro por alporquia
}

\section{Indolbutyric acid concentration in the propagation of mume by air layering}

\author{
Edvan Alves Chagas ${ }^{1}$; Pollyana Cardoso Chagas²; \\ Rafael Pio ${ }^{3 *}$; José Emílio Bettiol Neto ${ }^{4}$
}

Resumo

\begin{abstract}
Alguns trabalhos foram desenvolvidos com o intuito de se propagar o umezeiro por estaquia, porém os resultados não foram animadores. O presente trabalho teve como objetivo verificar a viabilidade da propagação do umezeiro (Prunus mume sieb \& Zucc), clone IAC-10, por alporquia. Ramos lenhosos de aproximadamente um ano de idade, localizados na parte mediana da copa, foram utilizados para a confecção dos alporques. Realizou um anel com aproximadamente dois centímetros de largura (suprimindo apenas a casca do ramo), pincelando-se com diferentes concentrações de IBA $(0,1000$, 2000, 3000 e $4000 \mathrm{mg} \mathrm{L}^{-1}$ ), distribuídos em todo o anel com o auxílio de pincel. Os alporques foram envolvidos com esfagno umedecido, como substrato, cobertos e amarrados nas extremidades com plástico transparente. Após 90 dias da realização da alporquia, coletaram-se os seguintes dados biométricos: porcentagem de alporques vivos, enraizados, calejados e número médio de raízes por alporque. De acordo com os resultados obtidos, conclui-se que o umezeiro pode ser propagado por alporquia, devendo ser utilizado a concentração de $1000 \mathrm{mg} \mathrm{L}^{-1}$ de IBA, a fim de propiciar maior enraizamento e número de raízes por alporque.
\end{abstract}

Palavas-chave: Prunus mume sieb \& Zucc, damasqueiro japonês, IBA e porta-enxerto

\begin{abstract}
Some research works were developed to propagate mume by cutting, even so the results were not exciting. The objective of present work was to verify the air layering in 'IAC-10' mume (japanese apricot) treated with different concentration of indolbutyric acid (IBA). In woody branches of approximately one year, air layering was accomplished with a $2 \mathrm{~cm}$ wide ring treated with IBA $(0,1,000 ; 2,000 ; 3,000$ and 4,000 $\mathrm{mg} \mathrm{L}^{-1}$ ), involved with humidified sphagnum moss, covered and tied in the extremities with transparent plastic film. After 90 days, percentage of survival air layering, rooting, callous and number of roots were evaluated. According to the results, mume can be propagated by air layering with a concentration of $1000 \mathrm{mg} \mathrm{L}^{-1}$ of IBA in order to provide a higher number of roots and a good rooting.
\end{abstract}

Key words: Prunus mume Sieb \& Zucc, Japanese apricot, IBA and rootstock

${ }^{1}$ Pesquisador Científico da Empresa Brasileira de Pesquisa Agropecuária, EMBRAPA CPAFRR. Boa Vista, RR. Bolsista Produtividade em Pesquisa CNPq. E-mail: echagas@cpafrr.embrapa.br

${ }^{2}$ Enga Agr ${ }^{\mathrm{a}}$, Doutoranda do curso de Fitotecnia, Universidade Federal de Lavras, UFLA. Lavras, MG. E-mail: pcchagas.eagro. ufrr@hotmail.com

${ }^{3}$ Prof. Adjunto do Depto. de Agricultura, UFLA, Lavras, MG. Bolsista Produtividade em Pesquisa CNPq. E-mail: rafaelpio@dag. ufla.br

${ }^{4}$ Pesquisador Científico do Centro Avançado de Pesquisa Tecnológica do Agronegócio de Frutas, Instituto Agronômico, IAC. Jundiaí, SP. E-mail: bettiolneto@iac.sp.gov.br

* Autor para correspondência 
O umezeiro (Prunus mume Sieb \& Zucc.) também conhecido por damasqueiro-japonês, pertence à família Rosaceae e gênero Prunus, como o pessegueiro, ameixeira, amendoeira e damasqueiro. Os frutos do umezeiro são de elevado amargor, acidez e aroma característico, comumente utilizados pelos povos orientais no preparo de conservas ("umeboshi”) e de um licor especial (“umeshu”) (CAMPO DALL'ORTO et al., 1998).

Oumezeiro apresenta características agronômicas importantes, como rusticidade, adaptação às regiões de inverno ameno, tipicamente em regiões de clima subtropical e elevada produtividade (CAMPO DALL'ORTO et al., 1998).

O umezeiro vem despertando grande interesse na persicultura, devido à possibilidade de ser utilizado como porta-enxerto para pessegueiro e nectarineira, sendo compatível com esta espécie e conferindolhe redução no porte das plantas, possibilitando assim a formação de pomares em alta densidade (CAMPO DALL'ORTO et al., 1992). Além destas vantagens, a utilização do umezeiro como portaenxerto de pessegueiro pode possibilitar a produção de frutos com maior massa e teor de sólidos solúveis, realçando a pigmentação vermelha da película, quando comparados aos frutos produzidos pelas mesmas copas enxertadas sobre o 'Okinawa', tradicionalmente utilizado como porta-enxerto no Estado de São Paulo (CAMPO DALL'ORTO et al., 1994).

Além disso, foram relatados a imunidade de trinta cultivares de umezeiro à galha-bacteriana ou galha-de-coroa, causada por Agrobacterium tumefaciens (E.F.Sm. and Town.) e resistência a nematóides-de-galha, o que foi comprovado para Meloidogyne incognita Raça 2 e M. javanica, características estas de grande importância para a seleção de porta-enxertos para frutífera do gênero Prunus (SHERMAN; LAYNE, 1983; ROSSI; FERRAZ; MONTALDI, 2002).

Estudos de compatibilidade e desenvolvimento no campo, realizados no IAC, revelaram grande variabilidade genética das sementes do umezeiro, o que resultaram em plantas com acentuadas diferenças de vigor no campo, sugerindo a necessidade de propagação clonal (CAMPO DALL'ORTO et al., 1992).

Alguns trabalhos foram desenvolvidos com o intuito de se propagar o clone de umezeiro IAC-5 por estaquia, porém os resultados não foram animadores, uma vez que não foi observado sucesso na formação de raízes nas estacas, onde se conseguiu apenas 30 de estacas enraizadas e emissão de três raízes por estaca (MAYER; PEREIRA, 2003). Sendo assim, seria necessária a adoção de técnicas auxiliares de propagação vegetativa, como a alporquia, para assim se obter sucesso na multiplicação desse clone de umezeiro.

Segundo Fachinello et al. (1995), a propagação pelo método de alporquia apresenta vantagens em relação à estaquia, dentre as quais estão: o alto percentual de enraizamento e a independência de infra-estrutura (casa de vegetação com sistema de nebulização). Castro e Silveira (2003), obtiveram sucesso na propagação dos pessegueiros 'Chirua' e 'Maciel' propagados por alporquia, chegando a índices de $100 \%$ de enraizamento.

Assim, o presente trabalho objetivou avaliar a viabilidade da técnica de alporquia no umezeiro, clone IAC-10, através da utilização de diferentes concentrações de IBA.

O presente trabalho foi desenvolvido nas dependências do Centro Avançado de Pesquisa do Agronegócio de Frutas do Instituto Agronômico (IAC), Jundiaí-SP, entre os meses de setembro e dezembro de 2005.

Ramos lenhosos de aproximadamente um ano de idade, localizados na parte mediana da copa, de plantas de sete anos de idade do clone IAC10 de umê, foram utilizados para a confecção dos alporques.

Os ramos foram anelados, produzindo-se um anel com aproximadamente dois centímetros de 
largura (suprimindo apenas a casca do ramo). A região anelada foi pincelada com diferentes concentrações de IBA $(0,1000,2000,3000$ e 4000 $\left.\mathrm{mg} \mathrm{L} \mathrm{L}^{-1}\right)$, distribuídos em todo o anel com o auxílio de pincel. Os alporques foram envolvidos com esfagno umedecido, como substrato, cobertos e amarrados nas extremidades com plástico transparente, com o intuito de se criar um ambiente úmido ao redor da lesão. Os alporques foram realizados aleatoriamente em plantas uniformes, utilizando-se ramos distribuídos nos quatro quadrantes da planta.

$\mathrm{O}$ delineamento utilizado foi o inteiramente casualizado, com cinco tratamentos (concentrações de IBA), quatro repetições e dez alporques por parcela, totalizando 200 alporques. As avaliações ocorreram após 90 dias da realização dos alporques, coletando-se os seguintes dados biométricos: porcentagem de alporques vivos, enraizados, formação de calos e número médio de raízes por alporque.

Os dados foram submetidos à análise de variância, as médias ao teste Tukey e as concentrações de IBA submetidas à regressão, ao nível de $5 \%$ de probabilidade. As análises foram realizadas pelo programa computacional - Sistema para Análise de Variância - SISVAR.

Pela análise estatística dos dados, verificou-se que apenas houve diferença significativa para a porcentagem de enraizamento e número de raízes por alporque.

Mesmo não havendo diferença estatística entre os tratamentos, foi registrado média de $87,05 \%$ para a porcentagem de sobrevivência e $86 \%$ para a formação de calos, notando-se assim que os resultados obtidos foram elevados nessas duas variáveis analisadas (Tabela 1).

Tabela 1. Porcentagem de sobrevivência e de formação de calos em alporques em umezeiro clone IAC-10 tratados com IBA. Jundiaí, Centro APTA Frutas/IAC, 2010.

\begin{tabular}{lcc}
\hline & $\begin{array}{c}\text { Concentrações de } \\
\text { IBA }\left(\mathrm{mg} \mathrm{L}^{-1}\right)\end{array}$ & Sobrevivência (\%) \\
\hline 0 & $85,25 \mathrm{a}^{*}$ & $83,00 \mathrm{a}$ \\
1000 & $100,00 \mathrm{a}$ & $100,00 \mathrm{a}$ \\
2000 & $93,75 \mathrm{a}$ & $93,75 \mathrm{a}$ \\
3000 & $81,25 \mathrm{a}$ & $81,25 \mathrm{a}$ \\
4000 & $75,00 \mathrm{a}$ & $72,00 \mathrm{a}$ \\
\hline Média & 87,05 & 86,00 \\
\hline $\mathrm{cv}(\%)$ & 13,10 & 14,28 \\
\hline
\end{tabular}

* Médias seguidas pela mesma letra em minúsculo na coluna não diferem entre si pelo teste Tukey ao nível de 5\% de probabilidade. Fonte: Elaboração dos autores.

Comparando-se os resultados do presente trabalho com a estaquia herbácea do clone de umezeiro IAC-10, em relação a formação de calos, a alporquia demonstrou-se mais eficiente, já que Mayer,Pereira e Nachtigal (2001) conseguiu apenas duas estacas com calo, em 320 estacas.
Quanto ao enraizamento, houve 43,95\% de alporques enraizados com a utilização de $1000 \mathrm{mg}$ $\mathrm{L}^{-1}$ de IBA, acréscimo de $6,83 \%$ quando comparado à ausência do tratamento com a auxina em questão. Em concentrações superiores, houve decréscimo no enraizamento dos alporques, o que levou a queda em concentrações superiores de IBA do enraizamento dos alporques (Figura 1). 
Figura 1. Porcentagem de enraizamento obtida em alporquia do umezeiro, clone IAC-10, tratados com IBA. Jundiaí, Centro APTA Frutas/IAC, 2010.

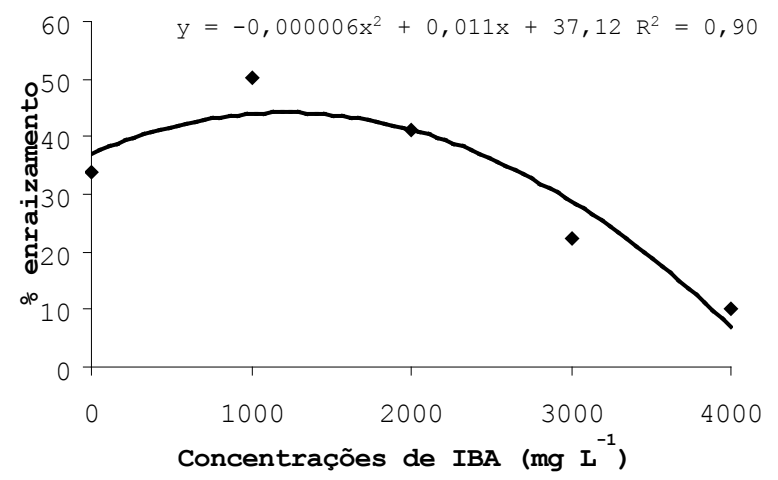

Fonte: Elaboração dos autores.

Resultados semelhantes ao enraizamento dos alporques foram constatados para o número de raízes, obtendo-se aproximadamente duas raízes por alporque com a utilização de $1000 \mathrm{mg} \mathrm{L}^{-1}$ de IBA (Figura 2).

Figura 2. Número de raízes obtida em alporquia do umezeiro, clone IAC-10, tratados com IBA. Jundiaí, Centro APTA Frutas/IAC, 2010.

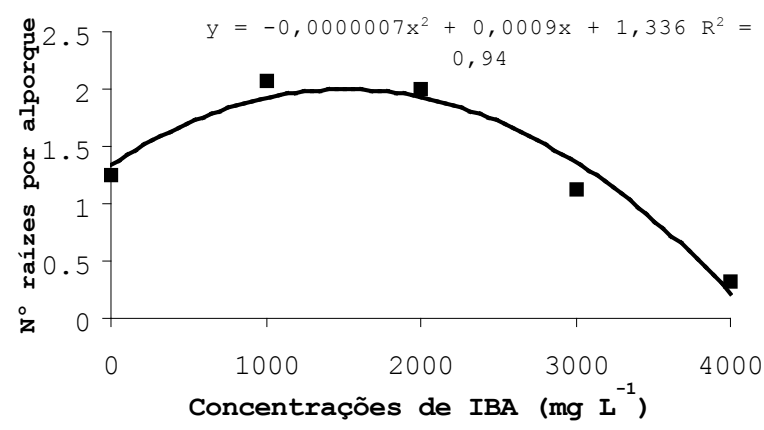

Fonte: Elaboração dos autores.

Comparando-se o número de raízes por alporque do clone IAC-10 com a alporquia realizadas em pessegueiro, cultivares Chirua e Maciel, houve formação de raízes vigorosas e em grande número em todos os alporques, no caso dos pessegueiros (CASTRO; SILVEIRA, 2003) e, para o umê, apenas duas raízes por alporque (Figura 2). Nesse sentido, nota-se que o potencial rizogênico é variável entre espécies do gênero Prunus. O mesmo ocorre quanto a emissão de raízes das estacas dessas duas espécies. Mayer e Pereira (2003) registraram a emissão de três raízes em estacas herbáceas herbácea do clone de umezeiro IAC-5 tratadas com $2000 \mathrm{mg} \mathrm{L}^{-1}$ de IBA, enquanto Dutra, Kersten e Fachinello (2002) registraram a emissão de aproximadamente 150 raízes em estacas do pessegueiro 'Capdeboscq' tratadas com $1000 \mathrm{mg} \mathrm{L}^{-1}$ de IBA. As vantagens do uso do IBA já foi relatado em outras frutíferas (KOTZ et al., 2011).

Relacionando os resultados obtidos com a utilização do IBA no enraizamento dos alporques de umezeiro clone IAC-10, com a propagação do umezeiro via estaquia, nota-se pela literatura a influência positiva do IBA no enraizamento. Miranda et al. (2000), que o utilizaram em estacas lenhosas de umezeiro, obtiveram maior enraizamento com a concentração de $2000 \mathrm{mg} \mathrm{L}^{-1} \mathrm{de}$ IBA; Suriyapananont (1990), estudando diferentes reguladores de crescimento na propagação do umezeiro, comprovou que o IBA aumentou o enraizamento nas concentrações entre 1500 e 3000 $\operatorname{mg~L^{-1}}$.

De acordo com os resultados obtidos, conclui-se que o umezeiro pode ser propagado por alporquia, devendo ser utilizado a concentração de $1000 \mathrm{mg}$ $\mathrm{L}^{-1}$ de IBA, a fim de propiciar maior enraizamento e número de raízes por alporque.

\section{Referências}

CAMPO DALL'ORTO, F. A.; OJIMA, M.; BARBOSA, W.; MARTINS, F. P. Damasco-japonês (umê) em São Paulo: opção para o século 21. O Agronômico, Campinas, v. 47, p.18-20, 1998.

. O nanismo do pessegueiro induzido pela enxertia no damasqueiro-japonês. Pesquisa Agropecuária Brasileira, Brasília, v.27, n. 3, p. 517-521, 1992.

CAMPO DALL'ORTO, F. A.; OJIMA, M.; BARBOSA, W.; MARTINS, F. P.; FOBÉ, L. A. Comportamento 
de pessegueiros IAC enxertados no damasqueirojaponês e no pessegueiro 'Okinawa'. In: CONGRESSO BRASILEIRO DE FRUTICULTURA, 1., 1994, Salvador. Anais... Salvador SBF, 1994. p. 879-880.

CASTRO, L. A. S.; SIlVEIRA, C. A. P. Propagação vegetativa do pessegueiro por alporquia. Revista Brasileira de Fruticultura, Cruz das Almas, v. 25, n. 2, p. 368-370, 2003.

DUTRA, L. F.; KERSTEN, E.; FACHINELLO, J. C. Época de coleta, ácido indolbutírico e triptofano no enraizamento de estacas de pessegueiro. Scientia Agricola, Piracicaba, v. 59, n. 2, p. 327-333, 2002.

FACHINELLO, J. C.; HOFFMANN, A.; NACHTIGAL, J. C.; KERSTEN, E.; FORTES, G. R. L. Propagação de plantas frutiferas de clima temperado. Pelotas: UFPel, 1995. $178 \mathrm{p}$.

KOTZ, T. E.; PIO, R.; CHAGAS, E.A.; CAMPAGNOLO, M. A.; BETTIOL NETO, J. E.; TADEU, M. H. Época de coleta das estacas, do uso de fitorregulador de enraizamento e de diferentes tipos de enxertos na produção de mudas de figueira 'Roxo de Valinhos'. Semina: Ciências Agrárias, Londrina, v. 32, n. 1, p. 2936, 2011.

MAYER, N. A.; PEREIRA, F. M. Enraizamento de estacas herbáceas de quatro clones de umezeiro (Prunus mume Sieb \& Zucc.) durante o inverno ameno, em Jaboticabal-SP. Revista Brasileira de Fruticultura, Cruz das Almas, v. 25, n. 3, p. 505-507, 2003.
MAYER, N. A.; PEREIRA, F. M.; NACHTIGAL, J. C. Propagação do umezeiro (Prunus mume Sieb \& Zucc.) por estaquia herbácea. Revista Brasileira de Fruticultura, Cruz das Almas, v. 23, n. 3, p. 673-676, 2001.

MIRANDA, C. S.; HOFFMANN, A.; COELHO, G. A.; NORBERTO, P. M.; CHALFUN, M. Z. H. Efeito do ácido indolbutírico e do substrato no enraizamento de estacas lenhosas de umezeiro (Prunus x Mume, Sieb \& Zucc.). In: CONGRESSO BRASILEIRO DE FRUTICULTURA, 1., 2000, Fortaleza, Anais... Fortaleza: Embrapa Agroindústria Tropical, 2000. p. 595.

ROSSI, C. E.; FERRAZ, L. C. C. B.; MONTALDI, P. T. Resistência de frutíferas de clima subtropical e temperado a Meloidogyne incognita raça 2 e M. javanica. Arquivos do Instituto Biológico, São Paulo, v. 69, n. 2, p. 43-49, 2002.

SHERMAN, W. B.; LYRENE, P. M. Improvement of peach rootstock resistant to root-knot nematodes. Proceedings of the Florida State for Horticultural Society, Lake Alfred, v. 96, p. 207-208, 1983.

SURIYAPANANONT, V. Stem cuttings of japanese apricot as related to growth regulators, rooting media and seasonal changes. Acta Horticulturae, Turquia, v. 279, p. 475-480, 1990. 
